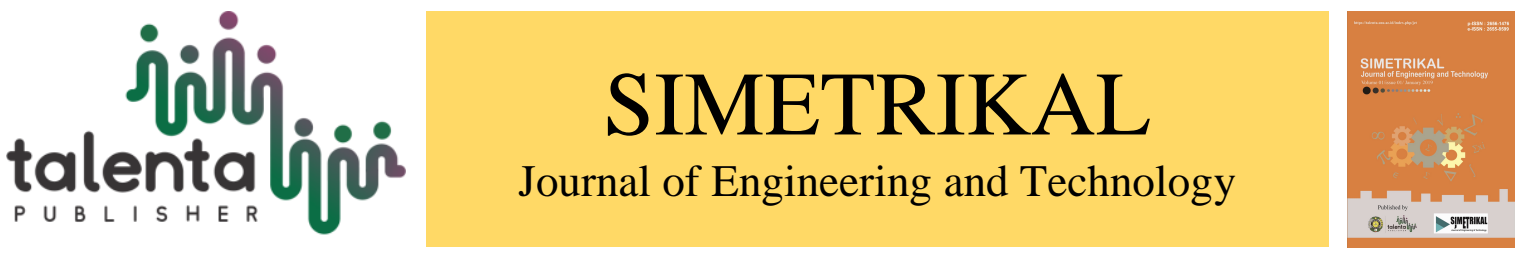

\title{
Rheological Properties of Polystyrene/Polypropylene (PS/PP) Blends: The Effects of Various Compatibilizers
}

\author{
Halimatuddahliana Nasution ${ }^{1}$, Hanafi Ismail ${ }^{2}$, and Ellsworth ${ }^{3}$ \\ ${ }^{1,3}$ Department of Chemical Engineering, Faculty of Engineering, Universitas Sumatera Utara \\ ${ }^{2}$ School of Materials and Mineral Resources Engineering, Universiti Sains Malaysia, Pulau Penang, \\ Malaysia
}

\begin{abstract}
Studies on rheological properties of polystyrene/polypropylene (PS/PP) blends with and without the addition of various compatibilizers were carried out. PS/PP blends of $20 / 80,50 / 50$ and $80 / 20$ (wt $\%$ ) were prepared through melt blending in a single screw extruder at a screw speed of $40 \mathrm{rpm}$ and temperature of $200{ }^{\circ} \mathrm{C}$. The rheologycal properties were evaluated by melt flow indexer machine with the temperature of $200{ }^{\circ} \mathrm{C}$. Four types of compatibilizers viz. polystyrene-block-poly (ethylene-butylene)-block-polystyrene (SEBS), surlyn, ethylene vinyl acetate (EVA) and sodium salt hydrate of 4 styrenesulfonic acid (ssh4 -ssh) were used in this study. The concentration of the compatibilizer is $7.5 \mathrm{wt} \%$. Results show for uncompatibilized blend, all blend compositions exhibit a reduction in melt viscosity, but the incorporation of EVA, surlyn and SEBS produced more resistance system to flow and increased the melt viscosity. However, in the presence of ssh-4-ssa a reduction in melt viscosity was observed, indicating easier for blend to flow.
\end{abstract}

Keyword: Rheologycal properties, Polypropylene, Polystyrene, Compatibilizer.

\begin{abstract}
Abstrak. Kajian mengenai sifat reologi campuran polistirena/polipropilena (PS/PP) dengan dan tanpa penambahan bahan penyerasi telah dilakukan. Campuran PS/PP disiapkan untuk perbandingan 20/80, 50/50 dan 80/20 menggunakan ekstruder single screw pada kecepatan $40 \mathrm{rpm}$ dan suhu $200{ }^{\circ} \mathrm{C}$. Sifat reologi campuran dievaluasi menggunakan alat melt flow indeks pada $200{ }^{\circ} \mathrm{C}$. Empat jenis bahan penyerasi telah digunakan pada kajian ini yaitu polystyrene-block-poly (ethylene-butylene)-blockpolystyrene (SEBS), surlyn, ethylene vinyl acetate (EVA) and sodium salt hydrate of 4 styrenesulfonic acid (ssh-4-ssh). Konsentrasi setiap bahan penyerasi yang digunakan adalah 7,5\%b. Hasil menunjukkan bahwauntuk campuran tanpa menggunakan bahan penyerasi menunjukkan penurunan viskositas lebur, tetapi dengan penambahan EVA, surlin, dan SEBS dihasilkan ketahanan aliran yang lebih baik dan viskositas yang meningkat. Namun dengan kehadiran ssh-4-ssapenuruan viskositas leburan terjadi yang menandakan campuran lebih mudah untuk mengalir.
\end{abstract}

Kata Kunci: Sifat reologi, Polipropilena, Polistirena, Bahan penyerasi

Received 11 September 2018 | Revised 16 January 2019| Accepted 31 January 2019

\footnotetext{
*Corresponding author at: Department of Chemical Engineering, University of Sumatera Utara, Jl. Almamater Kampus USU Medan, 20155, Sumatera Utara, Indonesia

E-mail address: h_dahliana@yahoo.com
} 


\section{Introduction}

Blending is an attractive method of creating new materials with more improvement and flexible performance, modified, and better properties than existing polymers. Thus, blends of thermoplastics play an increasingly important role in commercial applications.

Polymer blends can be characterized by their phase behaviors as being either miscible or immiscible. Only a few polymer blends are truly miscible to the molecular scale, for example, PPO/PS blend [1] or PVC/EVA blend [2]. Most polymer mixtures are either partially or fully immiscible, forming multiphase structures, for example, PVC/ABS blend [3] or PC/ABS blend [4].

The process of modifying interfacial properties of an immiscible polymer blend leading to the creation of polymer blend is called compatibilization [4]. The achievement of compatibilization, whether by addition of a third component (compatibilizer) or by inducing in situ chemical reaction between blend components (reactive blending), has played a pertinent role in the development of polymer blend [3][4].

The commercial production of polymer blend is normally done in the same melt processing machinery used with pure polymers, however in most intervenes having different configurations. Unexpected chemical and rheological problems can develop when certain materials are blended together.

It is generally believed that incompatibility prevails for two chemically dissimilar polymers in the molten state. Hence, the two systems polystyrene/polypropylene blend (PS/PP blend), considered in this work are easily conceivable as incompatible, because the structure of PS (contain benzene rings) belongs to the aromatic group, while PP contains straight carbon chains belonging to the aliphatic groups. It is also worth noting that one component, PS, is amorphous and brittle polymer, while the other component, $\mathrm{PP}$, is semi-crystalline and ductile polymer. The combination of brittle and ductile polymers does not always result in toughened blends. The stress-strain behavior for such blends typically indicates the poorer property systems changes to better one on addition of compatibilizer [5].

Compatibilization is a process of modification of interfacial properties of an immiscible polymer blend leading to the creation of a polymer blend [5]. The addition of compatibilizer influences adhesion between two incompatible polymers. There are several effects by using compatibilizer [6] [7]: reduce the interfacial tension in the melt, increase the adhesion at phase boundaries, and stabilize the dispersed phase against growth during annealing. 
Mixture of polystyrene/polypropylene in molten state results an immiscible and incompatible blend, which is due to the different structure of the homopolymers. Polystyrene is an amorphous and brittle polymer, whereas polypropylene is a semi-crystalline and ductile polymer. Works on polystyrene/polypropylene (PS/PP) blend are numerous. However, the additions of various compatibilizers to the blend in the various blend compositions are rarely done.

There are four compatibilizers were used for this work. They are surlyn, polystyrene-blockpoly(ethylene-butylene)-block-polystyrene (SEBS), ethylene vinyl acetate (EVA), and sodium salt hydrate of 4 styrenesulfonic acid (ssh-4-ssa).

SEBS and EVA, as copolymers, were chosen based on the segments in copolymer that chemically identical or similar to polystyrene and polypropylene. Since surlyn and ssh-4-ssa have polar and non-polar segments, it may interact with polystyrene and polypropylene.

The flow behavior of mixture of two incompatible uncrosslinked polymers can be very complex and unpredictable. The dispersed phase need not be spherical in shape and its morphology may change with concentration and rate of shear [8][9][10][11]. There can be inversion of the phases, or both polymers can be continuous phases. In flowing system, the low viscosity components tend to become the continuous phase and to encapsulate the high viscosity component and thus the overall viscosity of the mixture is reduced. This effect is the result of the principle that systems tend to reduce their dissipation energy to a minimum. Therefore, in capillary flow, the low viscosity component tends to collect near the high shear region at the wall while the high viscosity polymer collects in center as a core.

The rheological behavior of polymer blends, non-Newtonian, depends on the structure which is primarily governed by degree of dispersion of the components and by the mode of their preparation. Owing to the high viscosity of the system, it may prove to be in the thermodynamically non-equilibrium state and sometimes anomalous situations are observed.

\section{Methods}

Polypropylene (TITANPRO 6431 grade), polystyrene (Poly-Star HH-30G grade) and surlyn were supplied from DuPont Company in pellet form, EVA (ELVALOY 4924) and SEBS were purchased from Aldrich Chem. Co. Inc. in powder form.

Three different blends compositions were used viz. 20/80, 50/50 and 80/20 PS/PP. They were dry-mixed in a small cup before being fed into the extruder. The blends were prepared by mixing the appropriate amounts of binary (PP/PS) or ternary (PP/PS/compatibilizer) mixtures through melt blending in a single screw at a screw speed of $40 \mathrm{rpm}$. The compatibilizer concentration of $7.5 \mathrm{wt} \%$ (based on total weight of the blend) was employed. The blend 
temperature of $200^{\circ} \mathrm{C}$ was chosen based on the most suitable melt temperature according to the mechanical and rheological properties of the homopolymers.

The main aim here was to elucidate the rheological properties of PS/PP blend with and without compatibilizer. Prior to the binary (PS/PP) and ternary (PS/PP/compatibilizer) blends, the rheological studies of the homopolymers (PS and PP) were done to determine the most suitable temperature for the blends. Rheological properties such as apparent shear stress $\left(\tau_{\mathrm{a}, \mathrm{w}}\right)$ and apparent shear rate $\left(\gamma_{\mathrm{a}, \mathrm{w}}\right)$ of PS/PP blends with and without compatibilizers were measured using the Ray Ran Melt Flow Indexer at various stresses or loads. In order to use the MFI as a rheological machine, a few assumptions were made. These are: the fluid inside the capillary is Newtonian; the temperature at any one time is isothermal; the fluid is incompressible; no slippage occurred at the wall of the capillary.

The $\tau_{\mathrm{a}, \mathrm{w}}$ and $\gamma_{\mathrm{a}, \mathrm{w}}$ can be determined by considering the extrusion pressure and volumetric flow rate respectively. These parameters were calculated according to the following equations:

$$
\begin{aligned}
& \tau_{a, w}=\frac{\Delta P}{2 L / R} \\
& \dot{\gamma}_{a, w}=\frac{4 Q}{\pi R^{3}}
\end{aligned}
$$

$\mathrm{L}$ and $\mathrm{R}$ are the length and radius of the die respectively, $\pi=22 / 7$, while the other symbols maintain their meanings. The ratio of the length of the die to the radius of the die $=7.62$.

Since the homopolymers as well as the blends melted are non-Newtonian fluids, a correction has to be done. Here, Rabinowitch correction for converting the Newtonian wall shear rate to the "true wall shear rate" was used. Hence, the equation (3) can be replaced by equation (4) where $\mathrm{n}$ is the power law index.

$$
\dot{\gamma}_{c, t}=\dot{\gamma}_{a, w}\left[\frac{3 n+1}{4 n}\right] \quad\left(\sec ^{-1}\right)
$$

The true melt viscosity will be shown as in equation (4).

$$
\eta_{c, t}=\frac{\tau_{a, w}}{\dot{\gamma}_{c, t}}
$$




\section{Results and Analysis}

\subsection{Rheological Properties}

The effect of adding various compatibilizers on rheological properties of PS/PP blend are presented in various figures viz. shear stress versus shear rate curve, melt viscosity versus shear rate curve and melt viscosity versus blend composition curve as will be discussed below.

\subsubsection{Shear Stress - Shear Rate Curve}

The variation of shear stress with shear rate of the uncompatibilized and compatibilized blends at PS/PP blend compositions of 20/80, 50/50 and 80/20 are shown in Figures 1, 2 and 3, respectively.

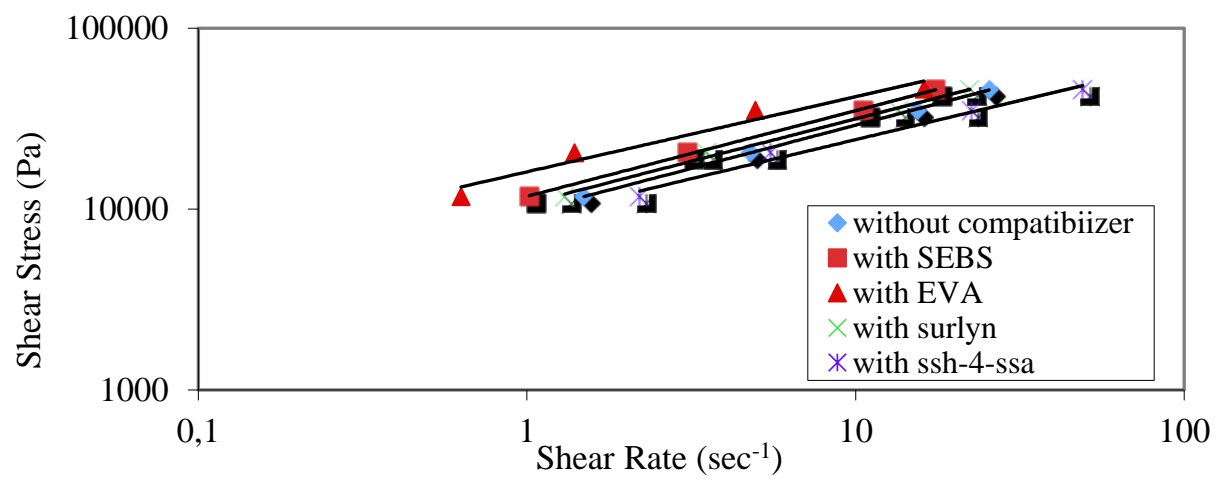

Figure 1 Effect of adding various compatibilizers (7.5wt\%) on the melt flow curve of $20 / 80 \mathrm{PS} / \mathrm{PP}$ blend at $200^{\circ} \mathrm{C}$

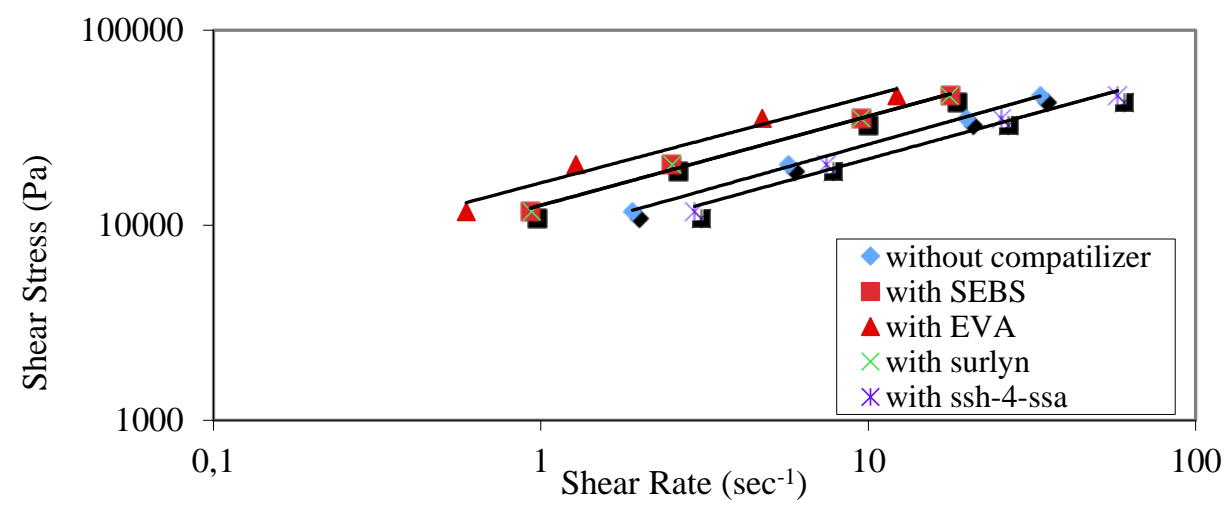

Figure 2 Effect of adding various comptibilizers ( $7.5 \mathrm{wt} \%)$ on the melt flow curve of 50/50 PS/PP blend at $200^{\circ} \mathrm{C}$

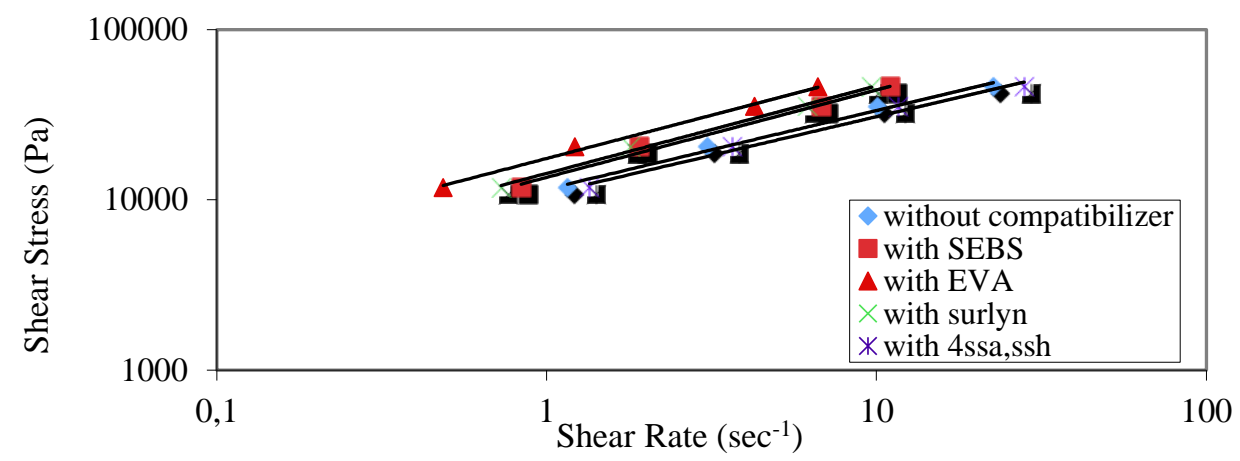

Figure 3 Effect of adding various compatibilizers (7.5wt $\%$ ) on the melt flow curve of $80 / 20 \mathrm{PS} / \mathrm{PP}$ blend at $200^{\circ} \mathrm{C}$ 
All the figures follow the power law relationship and the melt flow curves are linear over the entire range of shear stresses investigated, where increase in shear stress resulted in increased in shear rate. At all blend compositions studied (see Figures 1 - 3), the melt flow curves of the compatibilized blends with surlyn, SEBS and EVA lie above those of the uncompatibilized blends, indicating higher restriction in melt flow. Generally, the higher increase in shear stress with increase in shear rate of the compatibilized blend over the uncompatibilized blend implies restriction the flow of the blend. Among those curves, the compatibilized blends with EVA appeared above those of others. This indicates that the compatibilized blends with EVA produced a system which was more resistant to flow in comparison to the other blends. The melt flow curves of compatibilized blends with surlyn and SEBS lie above those of uncompatibilized, indicating more restriction the flow of the blends in comparison to uncompatibilized blends. However, adding ssh-4-ssa to the blends produced greater improvement in melt flow, with the curves lying below those of the uncompatibilized blends.

Figure 1 shows the effect of adding compatibilizers on the melt flow curve at 20/80 PS/PP blend. All curves are linear over the entire range of the shear rates studied. The figure exhibits that the curve of the compatibilized blend with ssh-4-ssa lies below that of the uncompatibilized blend. This indicates that at PP-rich blend composition, the introduction of ssh-4-ssa increased the melt flow effectively in comparison to the others. It is interesting to note however, that although the melt flow curve of compatibilized blend with ssh-4-ssa lies below that of the uncompatibilized blend, at higher shear rate the curve tended to clearly separate out. This indicates that at higher shear rates, the melt flow of the blend increased considerably. Here, the compatibilizer might be act as a lubricant. The flow curve of compatibilized blend with surlyn lies closely above that of the uncompatibilized blend, implying a slightly higher restriction to melt flow than the uncompatibilized blend. In the presence of SEBS, the curve lies closely above that of the compatibilized blend with surlyn. This indicates a slightly higher restriction in melt flow of this blend in comparison to the blend compatibilized with surlyn. In the case of adding EVA to such a blend, the curve tended to separate out at lower shear rate. This implies that adding EVA as compatibilizer produced a very significant restriction in melt flow compared to others at low shear rate. However, the curve of compatibilized blend with EVA lies closer to that of SEBS at higher shear rates. This indicates that the curve tended to merge with the melt flow curve of the compatibilized blend with SEBS at higher shear rates.

Figure 2 shows the effect of various compatibilizers on the melt flow curve for the 50/50 PS/PP blend. All the curves are also linear over the entire range of shear rates studied. However, in this case, the melt flow curves of compatibilized blend with SEBS and surlyn lie distinctly clear and above from that of the uncompatibilized blend. This indicates more restriction in flow the two compatibilized blends in comparison to their counterparts in the 20/80 PS/PP blend. This 
increase in melt viscosity is due to the increase in the stiffer PS content and hence a reduction in the PP content of the blend. It is also clear from the figure that the curves of the compatibilized blend with SEBS and surlyn lie closer to each other. It can thus be referred that both blends have comparable melt flows. The figure further shows that although the melt flow curve of EVA lies distinctly clear and above from the rest, the curve lies slightly closer to that of SEBS and surlyn at very higher shear rates. This indicates that the curve tended to merge with the melt flow curves of compatibilized blend with SEBS and surlyn at higher shear rates. In the other hand, the melt flow curve of compatibilized blend with ssh-4-ssa lies closer and below that of the uncompatibilized blend and tended to separate out at higher shear rates. However, their tendency to separate out is less than in the 20/80 PS/PP blend. This is due to the increase in the stiffer PS content which reduced the lubricating effect of the compatibilizer.

Figure 3 shows the effect of adding various compatibilizers on the melt flow curve of 80/20 PS/PP blend. For this intermediate blend, the same behavior is observed as in the 20/80 and 50/50 PS/PP blend. It is worth noting that the curve of the compatibilized blend with surlyn lies above that of the compatibilized blend with SEBS even at lower shear rates. This indicates the effect of surlyn to the melt flow of the 80/20 PS/PP blend more pronounced than that of the SEBS. As in the previous cases, the curve of the compatibilized blend with ssh-4-ssa lies below those of the other compatibilizers, including that of the incompatibilized blend. It is also clear from the figure that the lubricating effect of ssh-4-ssa was reduced because of the increase in the PS content of the blend.

\subsubsection{Melt Viscosity - Shear Rate Curves}

The variations of melt viscosity with shear rate at PS/PP blend composition of 20/80, 50/50 and 80/20 with and without addition of compatibilizers are shown in Figures 4, 5 and 6, respectively. 


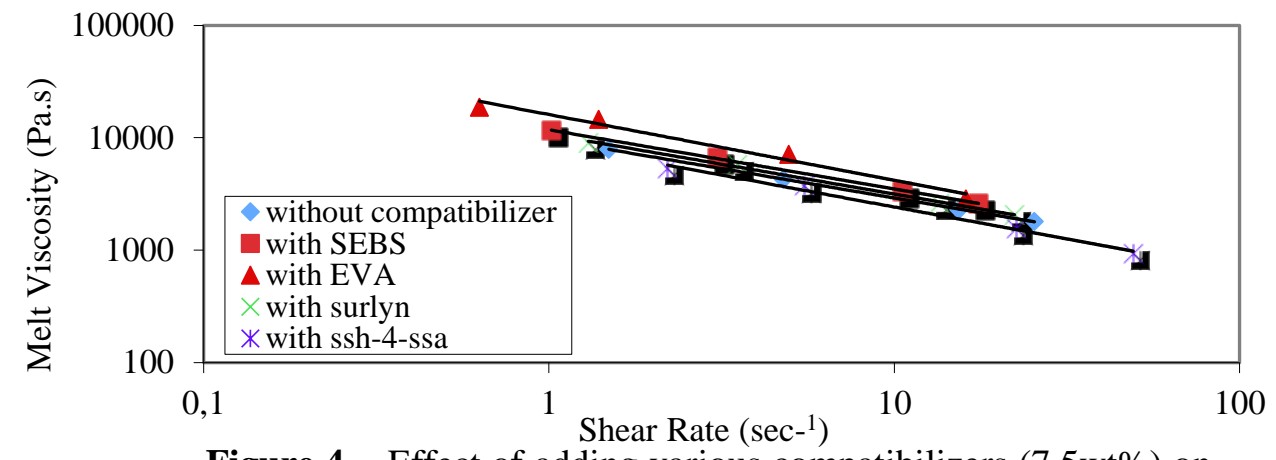

Figure 4 Effect of adding various compatibilizers $(7.5 \mathrm{wt} \%)$ on the melt viscosity of $20 / 80 \mathrm{PS} / \mathrm{PP}$ blend at $200^{\circ} \mathrm{C}$

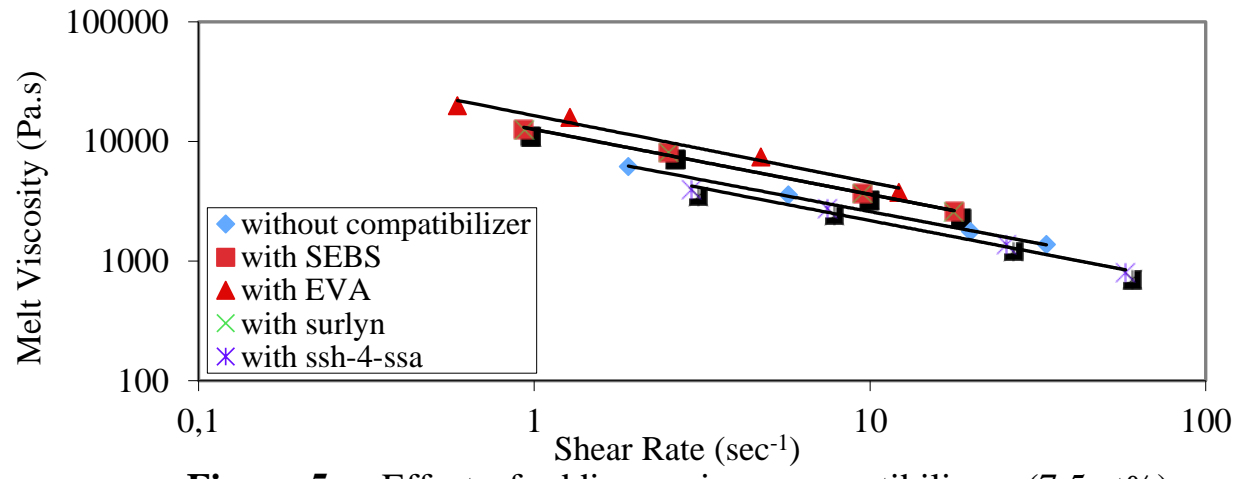

Figure 5 Effect of adding various compatibilizers (7.5wt\%) on the melt viscosity of $50 / 50 \mathrm{PS} / \mathrm{PP}$ blend at $200^{\circ} \mathrm{C}$

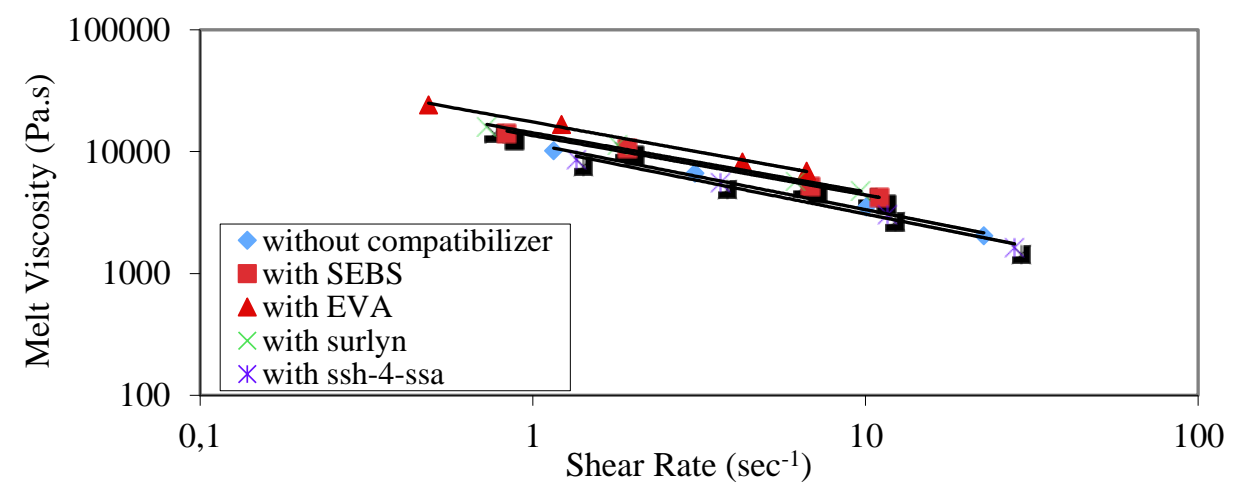

Figure 6 Effect of adding various compatibilizers $(7.5 \mathrm{wt} \%)$ on the melt viscosity of $80 / 20 \mathrm{PS} / \mathrm{PP}$ blend at $200^{\circ} \mathrm{C}$

At all blend composition studied (Figures $4-6$ ), the curves of melt viscosity of the blends with addition compatibilizers (with the exception of compatibilized blend with ssh-4-ssa) lie above those of the uncompatibilized blends. This indicates that these blends have higher melt viscosity than the uncompatibilized blends. The curves of compatibilized blends with addition EVA lie above those of others, indicating higher melt viscosity. The melt viscosity of compatibilized blends with surlyn or SEBS are higher than those of uncompatibilized, indicating higher melt viscosity in comparison to uncompatibilized blends. However, on the addition of ssh-4-ssa as compatibilizer, the curves of blends lie below of the others, indicating lower melt viscosity.

Figure 4 shows the effect of adding compatibilizer on the melt viscosity of 20/80 PS/PP blend. The figure exhibits that all the curves are linear over the entire range of shear rates studied. In the case of adding surlyn, the melt viscosity of the blend lies closely above to the 
uncompatibilized blend, indicating a slightly higher melt viscosity than the uncompatibilized blend. In the case of adding SEBS, the curve lies closely above to the compatibilized blend with surlyn curve. This indicates that with the addition of SEBS produced higher melt viscosity in comparison with surlyn. On the other hand, the addition of EVA increased of the melt viscosity for all shear rates. It is interesting to see here that the curve of compatibilized blend with EVA lies closer to that of SEBS at higher shear rates. This indicates that these curves tended to merge at higher shear rates. In the presence of ssh-4-ssa a reduction in melt viscosity was observed, which made it easier for the blend to flow. It is worth noting that although the melt viscosity curve of compatibilized blend with ssh-4-ssa lies below that of uncompatibilized blend, at higher shear rate the curve tended to clearly separate out. This indicates that at higher shear rate, the melt viscosity of the blend reduced considerably.

Figure 5 shows the effect of adding various compatibilizers on the melt viscosity of 50/50 PS/PP blend. All the curves are also linear over the entire range of shear rates studied, where increase in shear rate resulted in decrease in melt viscosity. It is worth noting that the flow curves of surlyn and SEBS lie close to each other, indicating similar viscosity (but above that of the uncompatibilized blend). This implies the ability of SEBS and surlyn to equally influence the viscosity of this intermediate blend. The melt viscosity curve of ssh-4-ssa blend lie below that of the uncompatibilized blend, indicating lower viscosity and hence its lubricating effect. In the case of adding EVA to the blend, the curve tended to merge with the melt viscosity curves of the compatibilized blend with SEBS and surlyn at very higher shear rates.

Figure 6 shows the effect of adding various compatibilizers on the melt viscosity of 80/20 PS/PP blend. The same behavior is observed as in 20/80 and 50/50 PS/PP blends. Melt viscosity of the blends decreased with increase in shear rate. The melt viscosity of surlyn is higher than that of SEBS even at low shear rates. This indicates the ability of surlyn to influence the melt viscosity of this PS-rich blend is more than that of SEBS. In the case of adding ssh-4-ssa at the blend, the melt flow curve lies close below that of the uncompatibilized blend. Here, the lubricating effect of the compatibilizer was reduced because of the increase in the PS content of the blend.

\subsubsection{Melt Viscosity - Blend Composition Curves}

The effect of various compatibilizers on the cross-plot of melt viscosity and blend composition that is substituted with PS content for the uncompatibilized and compatibilized blends at fixed shear stresses of 11762 and $46144 \mathrm{~Pa}$ are shown in Figures 7 and 8, respectively. 


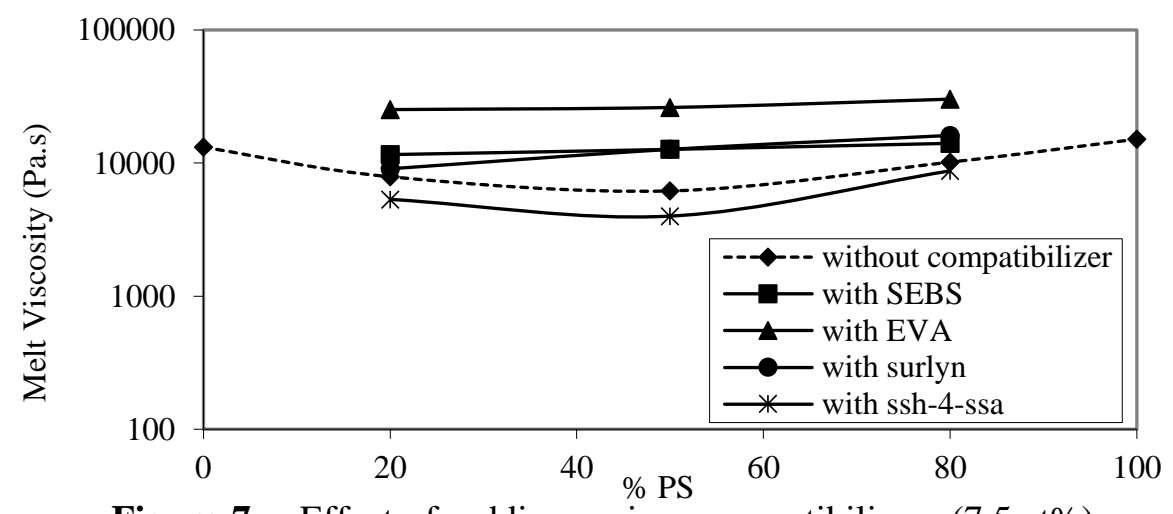

Figure 7 Effect of adding various compatibilizers (7.5wt\%) on the melt viscosity at different PS contents with a shear stress of $11762 \mathrm{~Pa}\left(200^{\circ} \mathrm{C}\right)$

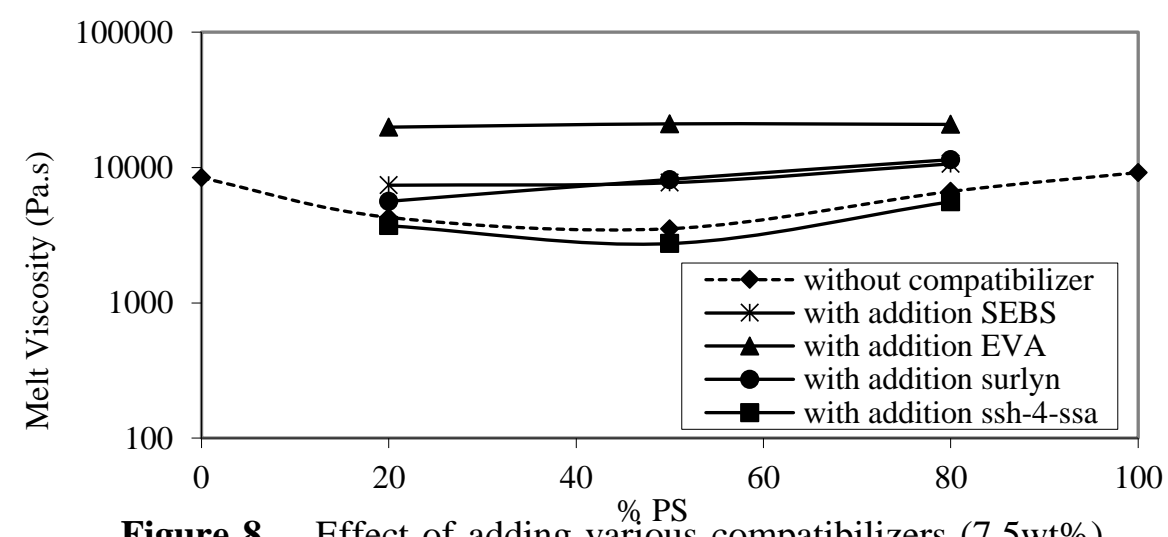

Figure 8 Effect of adding various compatibilizers (7.5wt\%) on the melt viscosity at different PS contents with a shear stress of $20448 \mathrm{~Pa}\left(200^{\circ} \mathrm{C}\right)$

Both figures show the curves of compatibilized blends lie above that of uncompatibilized blends (with exception of compatibilized blend with ssh-4-ssa). These figures show that on the introduction of SEBS or surlyn as compatibilizers an increase in melt viscosity resulted with increase of PS content. This indicates that besides the presence of compatibilizer, the PS content also played a significant role to the melt viscosity of the blend at all shear stresses of the blend. However, adding ssh-4-ssa to the blend shows low melt viscosity. The effect of the type of compatibilizer on the melt viscosity of the blends can be seen in the presence of EVA, where the melt viscosity lies above that of other compatibilizers and also higher than the PS and PP homopolymer. This indicates that the melt viscosity of the compatibilized PS/PP with EVA was more influenced by the nature of compatibilizer.

From above discussion it can be concluded that a progressive increase in the melt viscosity with the addition of compatibilizers such as SEBS and surlyn owing to the improvement of the interfacial viscosity. The increase in melt viscosity must originate from new and stronger interactions provoked by the presence of the compatibilizers. In other word, the analysis of the melt viscosity as a function of shear rate reflects the existence of a process of compatibilization between PS and PP in the presence of compatibilizer. This can also be connected with an increase of mechanical properties of the blends. 
The role of SEBS in increasing melt viscosity seems attributable to the elastomeric nature of this copolymer, which in its molten state is capable of absorbing greater energy of deformation. In the case of adding EVA at the blends, the increase in melt viscosity might be attributed to the high viscosity of the compatibilizer. The melt viscosity of EVA is higher than PS homopolymer and it might be able to restrict the melt flow of the blend. However, a reduction in the melt viscosity with the addition of ssh-4-ssa owing to the compatibilizer appeared to act as a lubricant and diminishing the overall melt viscosity of the blend. This is found to be true as the mechanical properties of the blend are lower than the others.

\section{Conclusion}

The incorporation of various additives into PS/PP blend gives different effect to rheological behavior. A more significant improvement of the melt viscosity of PS/PP blend with addition EVA was observed. An improvement also was displayed by PS/PP blend either with SEBS or surlyn. However, the addition of ssh-4-ssa to the blend showed a reduction in melt viscosity.

\section{REFERENCES}

[1] J. Yang, L. An, and T. Xu, "The glass transition temperatures of PS/PPO blends: Couchman volume-based equation and its verification," Polymer (Guildf)., vol. 42, no. 18, pp. 7887-7892, 2001.

[2] Q. F. An, J. W. Qian, H. B. Sun, L. N. Wang, L. Zhang, and H. L. Chen, "Compatibility of PVC/EVA blends and the pervaporation of their blend membranes for benzene/cyclohexane mixtures," J. Memb. Sci., vol. 222, no. 1-2, pp. 113-122, 2003.

[3] A. R. Gawade, A. V. Lodha, and P. S. Joshi, "PVC/ABS blends: Thermal and morphological studies," J. Macromol. Sci. Part B Phys., vol. 47, no. 1, pp. 201-210, 2008.

[4] R. Krache and I. Debah, "Some Mechanical and Thermal Properties of PC/ABS Blends," Mater. Sci. Appl., vol. 02, no. 05, pp. 404-410, 2011.

[5] J. D. Martin and S. S. Velankar, "Effects of compatibilizer on immiscible polymer blends near phase inversion," J. Rheol. (N. Y. N. Y)., 2007.

[6] Abdul Razak N C, Inuwa I M Hassan A, Samsudin S A, "Effects of Compatibilizers on Mechanical Properties of PET/ PP Blend," Compos. Interface, vol. 20, pp. 507-515, 2013.

[7] T. Yoo, H. Yoon, S. Choi, M. Kim, Y. Kim, and W. Kim, "Effects of compatibilizers on the mechanical properties and interfacial tension of polypropylene and poly(lactic acid) blends," Macromol. Res., 2010.

[8] P. Van Puyvelde, S. Velankar, and P. Moldenaers, "Rheology and morphology of compatibilized polymer blends," Current Opinion in Colloid and Interface Science. 2001.

[9] C. L. DeLeo and S. S. Velankar, "Morphology and rheology of compatibilized polymer blends: Diblock compatibilizers vs crosslinked reactive compatibilizers," J. Rheol. (N. Y. N. Y)., 2008.

[10] W. N. K. Seok J Y, Seung H L, Minho J, Heon S L, "Morphology and rheology of compatibilized polymer blends: Diblock compatibilizers vs crosslinked reactive compatibilizers," Macromol. Res., vol. 21, pp. 1182-1187, 2013.

[11] B. Y. Shin, R. Narayan, S. Il Lee, and T. J. Lee, "Morphology and rheological properties of blends of chemically modified thermoplastic starch and polycaprolactone," Polym. Eng. Sci., 2008. 